\title{
Cardiogenic shock treated with infusion of dextrose solution
}

\author{
P. G. F. Nixon H. IKram S. Morton \\ Cardiac Department and Intensive Care Ward, Charing Cross Hospital, London
}

THE TERM shock in acute myocardial infarction is used here to describe a syndrome of pallor, hypotension, restlessness and disturbance of consciousness, intense peripheral vasoconstriction and anuria, with or without elevation of the central venous pressure. Metabolic acidosis is an invariable concomitant. Death is likely to follow upon the appearance of the signs, unless they arise from a syncopal reaction that can be treated by altering the posture, or a dysrhythmia that can be corrected. The incidence of shock in cardiac infarction is said to be $15 \%$, and the mortality 88\% (Epstein \& Relman, 1949). The true mortality is probably nearer to $100 \%$ because authors may have included cases of syncope, or of hypotension secondary to a dysrhythmia.

It is worthwhile to treat the hypotension because it predisposes to metabolic acidosis, dangerous dysrhythmia and renal failure; reduces the collateral blood flow to the ischaemic area (Estes et al., 1966); reduces the contractility of the myocardium supplied by narrowed coronary vessels (Hellerstein, Brofman \& Caskey, 1962); and increases the systolic ballooning of the infarcted area (Corday, Bergman \& Kruger, 1949). Therapeutic optimism is encouraged by the observation that the syndrome is commoner in branch occlusions of a coronary artery than in mainstem obstruction (Kurland, Weingarten \& Pitt, $1965)$, and by the surprisingly rapid and complete recovery of successfully treated patients (Nixon, Ikram \& Morton, 1966).

The treatment has been approached in various ways, by transfusion, by vasoconstrictive drugs, and by inotropic agents. Transfusion passed out of favour when blood volume measurements failed to show deficits, and vasoconstriction was said to be beneficial even though intense vasoconstriction is the most striking physical sign. In our hands the vasoconstrictive drugs have neither saved advanced cases of the syndrome nor have they halted the progression of the metabolic acidosis that indicates the failure of the circulation. If we ever encounter cases of the syndrome where the heart function is adequate, and where vasodilatation is responsible for the hypotension, we shall be prepared to consider the use of vasoconstrictors!

Vasoconstrictive drugs with an inotropic action have yet to prove their value in cardiogenic shock.
Their greatest effect may be in the patients who are $\bar{\omega}$ syncopal from sedative drugs that encourage the pooling of blood in the patient nursed head up. 3 . Often it is difficult to wean patients off these drugs, and infusion is required before their administration can be stopped (Botticelli, Tsagaris \& Lange, 1965). The authors' experience suggests that infusion alone may be adequate treatment (Nixon et al., 1966). $\vec{N}$

In the authors' series of cases with advanced ${ }^{\circ}$ signs and raised central venous pressure, the patients were nursed supine and given oxygen to breathe. $\frac{D}{O}$ Five per cent dextrose was given intravenously by drip in doses of $50-200 \mathrm{ml}$ at a time. The rate of $\vec{\oplus}$ infusion was controlled by observation of the central venous pressure, the arterial pressure, the urine flow, and the clinical appearance of the peripheral circulation. It was not difficult to resuscitate each patient by using the lowest rate of infusion that improved the arterial pressure and the peripheral $\frac{}{\mathbb{D}}$ circulation, and restored the urine flow. Pulmonary oedema created neither a clinical nor a therapeutic $\overline{\bar{O}}$ problem, although transitory early signs may have appeared on the radiographs.

Each dose of the solution raised the arterial pressure and also the venous pressure. The latter was allowed to subside towards its original level before the next dose was given. The technique is reminiscent 3 of the treatment of hypotension at the end of heart and lung by-pass operations where blood is injected from the machine until a satisfactory level of arterial pressure is achieved. The venous pressure obtained at this point is maintained by intravenous infusion. $\frac{T}{2}$ If the injection from the machine fails to improve the arterial pressure, the venous pressure rises 'uselessly' $N$ and the procedure is abandoned.

After the resuscitation the authors found it neces- $N$ sary to continue the infusion for varying periods before the tendency to hypotension disappeared to leave a stable circulation. In the first case a total of $\stackrel{\bullet}{=}$

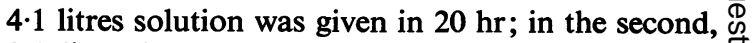
$2 \cdot 1$ litres in $12 \mathrm{hr}$; and, in the third, 12.3 litres in 1 week.

A fourth case, not previously described, is illustrative:

A 76-year-old man collapsed suddenly and was brought to hospital $2 \mathrm{hr}$ later at $\mathbf{1 9 . 0 0}$ hours. He was extremely ill and pale; the circulation in the ears, fingers and toes 8 
was greatly reduced; the systolic blood pressure lay between 90 and $100 \mathrm{mmHg}$; the mental condition varied between stupor and semi-conscious restlessness, and the rapidity of his deterioration was obvious. He had been at work earlier in the day, and preparing for his marriage, and it was decided to treat him vigorously. an indwelling needle was inserted into the brachial artery; and the bladder was catheterized.

Arterial blood analysis showed $\mathrm{pH} 7 \cdot 35$; oxygen saturation $97 \%$; and a metabolic acidosis of $-6.5 \mathrm{mEq} / 1$ as determined by the Siggard-Andersson nomogram. The acidosis was corrected with an intravenous infusion

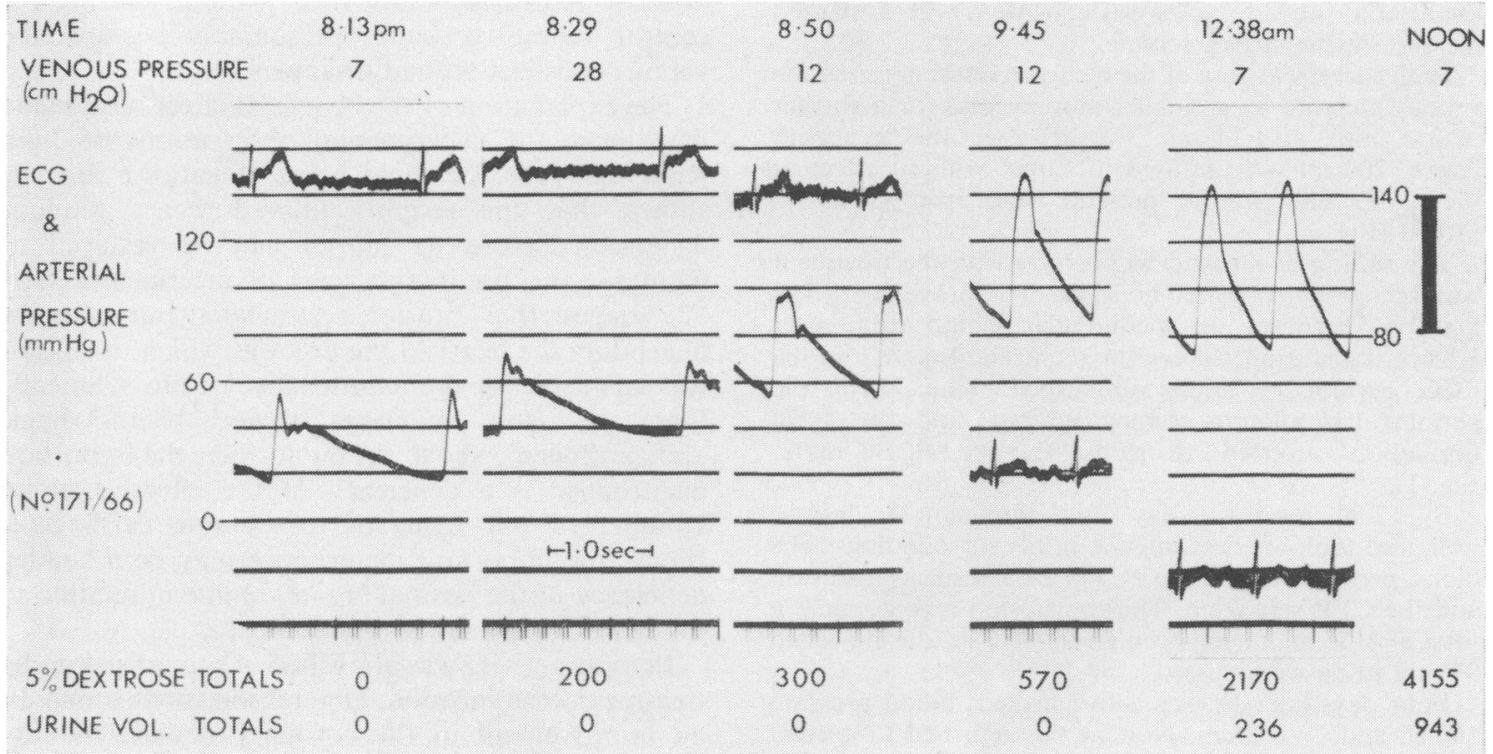

Fig. 1. The arterial pressure and the electrocardiogram during treatment with dextrose infusion. At corresponding times the total amounts of dextrose given and urine secreted are shown, together with the central venous pressure.

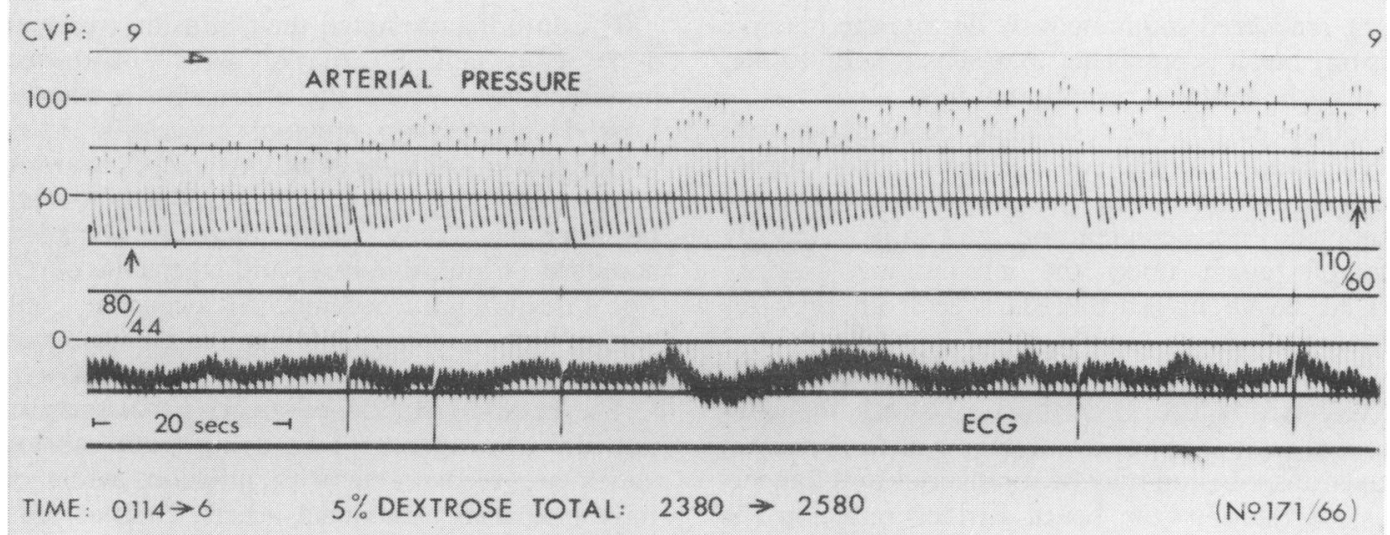

Fig. 2. A continuous recording of the arterial pressure and electrocardiogram from 01.14 to 01.16 hours during the infusion of $200 \mathrm{ml}$ dextrose. There was no detectable difference between the venous pressure at the beginning and the end of the infusion.

During his transfer to the Intensive-care suite, the heart rate slowed to $40 / \mathrm{min}$, the trunk became mottled with cyanotic patches of stasis, and the fingers and ears were blue. His supine position was maintained and the legs were elevated; oxygen was given by face-mask, and atropine sulphate $0.5 \mathrm{mg}$ was injected intravenously. His deterioration continued. A cardiac-catheter was introduced into the superior vena cava from an arm vein; of $8.4 \%$ sodium bicarbonate solution. The arterial pressure recorded with an electromanometer was 55/18 $\mathrm{mmHg}$, and the central venous pressure (CVP) $7 \mathrm{~cm}$ water above the zero level set at the sternal angle $(8.13$ p.m., Fig. 1). No urine was formed. The electrocardiogram (ECG) showed slow atrial fibrillation with ectopic beats, and a marked current of injury.

At 8.13 p.m. the infusion of $5 \%$ dextrose solution 
into the superior vena cava was begun, and the first 200 $\mathrm{ml}$ were given in $10 \mathrm{~min}$. This raised the CVP to $28 \mathrm{~cm}$, but also raised the arterial pressure to $70 / 40$ (8.29 p.m., Fig. 1). In $16 \mathrm{~min}$ the CVP fell to $12 \mathrm{~cm}$, and further doses of $100-200 \mathrm{ml} \mathrm{5 \%}$ dextrose were given. The arterial pressure reached a peak of $150 / 80$ (9.45 p.m., Fig. 1), the heart rate increased; and the change in the shape of the arterial pressure pulse was consistent with a marked increase in the stroke-volume.

Each successive dose of the dextrose solution raised the venous pressure by a smaller amount and for a shorter period until, at 1.14 a.m., $5 \mathrm{hr}$ after the treatment began, $200 \mathrm{ml}$ were infused in 2 min without affecting the CVP. The arterial pressure rose from $80 / 44$ to 110/60 (Fig. 2).

The raising of the arterial pressure with the treatment was accompanied by other signs of improvement. The first was recovery of mental clarity and calm after $\frac{1}{2} \mathrm{hr}$ of transfusion. After $2 \mathrm{hr}$ the urine flowed, and the ECG current of injury diminished. After $4 \mathrm{hr}$ the peripheral circulation seemed normal, and the atrial fibrillation reverted to sinus rhythm (12.38 a.m., Fig. 1).

By 12.00 noon the day after admission he looked well, and took an alert interest in his surroundings. The blood pressure was stable at $140 / 80$ without transfusion and the CVP was $7 \mathrm{~cm}$. The transfusion was stopped, a total of $4155 \mathrm{ml}$ having been given in $16 \mathrm{hr}$, during which $943 \mathrm{ml}$ urine were passed.

Four days later he was active in bed; blood pressure $160 / 85$ and CVP $2 \mathrm{~cm}$. Now he has returned to normal activity and is free from heart failure.

It may be considered that this patient, and the others, recovered spontaneously despite the massive infusion; but it is our belief that he was soon to die, and that the infusion resuscitated him.

Another patient was similarly resuscitated but died suddenly during convalescence. Two others failed to respond to the infusion and neither norepinephrine nor epinephrine had any clinically detectable effect upon the circulation. Autopsy revealed severe myocardial damage from previous infarctions.

It has been suggested that the presence of congestive heart failure in cardiogenic shock indicates a 'limited reserve of the circulatory system', and that intravenous infusion may be injudicious and dangerous, 'overdilating' the heart, further reducing the cardiac output and aggravating the shock (Berman \& Akman, 1952). In the patient described here the central venous pressure was abnormally high $\left(7 \mathrm{cmH}_{2} \mathrm{O}\right)$ at the start of the treatment, and yet the restoration of the blood pressure, peripheral circulation and urine flow, and his recovery, suggest that the transfusion was beneficial. This raises the question as to whether the elevation of the venous pressure really was a sign of congestive heart failure or whether it indicated some other phenomenon. We suggest that it was a sign of constriction of the venous system, the evidence being the great increase $\frac{\Phi}{c}$

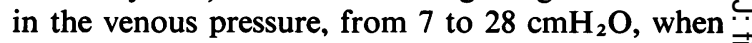
$200 \mathrm{ml} \mathrm{5 \%}$ dextrose first were added to the circulat- $\overrightarrow{\bar{s}}$ ing blood volume. This contrasts with the response $-\overrightarrow{0}$ at a later stage, after the circulation had improved $\overline{0}$ with the infusion of $2380 \mathrm{ml} 5 \%$ dextrose, when a $\overline{\bar{c}}$. dose of $200 \mathrm{ml}$ was absorbed without altering the $\Phi$ central venous pressure, presumably because the venous constriction had disappeared.

The explanation of the beneficial effect of infusion $\overrightarrow{0}$ may lie in the experimental observations of John $\overrightarrow{\vec{H}}$ Ross, Jr (1966, personal communication). He has $\stackrel{\omega}{\sigma}$ shown that the recently injured heart requires $\overline{0}$ distension before its output can be restored to 3 . maintain the pre-infarct level of arterial pressure. We suggest that infusion resuscitated our cases by distending the heart to the point at which its output $\biguplus_{\infty}$ was adequate for the maintenance of life. Clinically $i$ there are many similarities between haemorrhagic $\vec{N}$ and cardiogenic shock. In the former, the important $ᄋ$ disturbance is a deficiency of the effective blood volume. In our cases of recoverable cardiogenic $\rightarrow$ shock, the important disturbance may be a sudden deficiency of the normal blood volume in relation to $\vec{\bullet}$ the needs of the newly-injured heart.

Ectopic activity was abolished or minimized under treatment with infusion. One reason for this may be an improvement in the coronary circulation consequent upon the volume-expanding effect of the infused solution. Another reason may be the potassium-shifting or biochemical effect of the infused dextrose (Sodi-Pallares, 1961; Mitra, 1965).

The authors attempted their infusion treatment in 3 a desperate clinical situation where death seemed imminent, and where the alternative methods had proved valueless on previous occasions. They are aware that infusion may be extremely hazardous in acute cardiac infarction, and consider that it should $\frac{5}{3}$ be attempted only where there is an adequate standard of intensive-care; and where the complica- $\frac{\mathrm{O}}{3}$ tion of pulmonary oedema, if it occurred, could be treated with intermittent positive-pressure ventila- $\triangle$ tion.

The authors' experience suggests that some of the patients who appear to be dying from cardiogenic $N$ shock are recoverable with infusion, while others $N$ have irreparably damaged hearts. Neither the sizes $N$ nor the distinguishing signs of the groups are known ${ }^{\omega}$ at present. Tentatively it is suggested that a solution of $1 \mathrm{ml}$ of $1 / 1000$ epinephrine hydrochloride in $\mathrm{a} \stackrel{0}{ᄃ}$ $500 \mathrm{ml}$ unit of $5 \%$ dextrose may be dripped slowly intravenously in cases where one or two doses of ${ }^{-}$ dextrose solution have proved ineffective. The $\frac{0}{0}$ shocked case that responds neither to the volume- $\vec{D}$ expanding and biochemical effects of the dextrose $\frac{?}{\mathbb{P}}$ nor to the powerful inotropic effect of the epinephrine $\varrho$ probably has too little viable myocardium to survive without an artificial circulation. 


\section{References}

Berman, E.F. \& Akman, L.C. (1952) Intra-arterial infusion in treatment of shock resulting from coronary occlusion. Amer. Heart J. 43, 264.

BotTicelli, J.T., TsagaRis, T.J. \& LANGe, R.L. (1965) Mechanisms of pressor amine dependence. Amer. J. Cardiol. 16, 847.

Corday, E., Bergman, H.C. \& Kruger, H.E. (1949) Studies on coronary circulation; effect of shock on heart and its treatment. Amer. Heart J. 37, 560.

Epstein, F.H. \& Relman, A.S. (1949) Transfusion treatment of shock due to myocardial infarction. New Engl. J. Med. 241, 2889.

Estes, E.H., JR, Entman, M.L., Dixon, H.B. \& Hackel, D.B. (1966) The vascular supply of the left ventricular wall. Amer. Heart J. 71, 58.
Hellerstein, H.K., Brofman, B.L. \& Caskey, W.H. (1952) Shock accompanying myocardial infarction: treatment with pressor amines. Amer. Heart J. 44, 407.

Kurland, G.S., Weingarten, C. \& Pitt, B. (1965) The relation between the location of coronary occlusions and the occurrence of shock in acute myocardial infarction. Circulation, 31, 646.

Mitra, B. (1965) Potassium, glucose and insulin in treatment of myocardial infarction. Lancet, ii, 607.

Nixon, P.G.F., Ikram, H. \& Morton, S. (1966) Infusion of dextrose solution in cardiogenic shock. Lancet, i, 1077.

Sodi-Pallares, D. (1961) Possibility of a therapy of cellular ion integration in cardiovascular diseases. Arch. Inst. Cardiol. Mexico, 31, 577.

\section{Discussion to the papers by J. B. L. Howell; M. W. McNicol; and P. G. F. Nixon, H. Ikram and S. Morton}

GreEN. Dr Howell must be congratulated on giving us such a clear account of the theoretical basis of oxygen therapy and of the practical problems involved. There are, however, one or two points about his paper that I would like to raise.

With regard to the administration of oxygen, we have assessed a number of devices from the point of view of how easily one can predict the concentration of oxygen that they will deliver, whether this is appropriate in treating bronchitics, the degree of rebreathing produced and finally, but undoubtedly of great importance, how comfortable and convenient they are. We found that the patients unanimously preferred the nasal cannulae; one of the masks least liked was the Ventimask. The nasal cannulae proved equally as predictable as the Edinburgh mask and could be relied upon to give $27-40 \%$ oxygen with flows of between 1 and $4 \mathrm{l} / \mathrm{min}$, with sufficient accuracy for clinical use. It is now possible to obtain Ventimasks that deliver with incredible accuracy 24, 28 and $35 \%$ oxygen. I believe that the $24 \%$ Ventimask and a nasal cannula is all that is required for administering oxygen to bronchitics in respiratory failure, unless they need assisted ventilation. There is no need to resort to such things as head-tents, which both our patients and nurses have found very difficult to get on with.

Finally, our tendency recently has been to artificially ventilate these patients at a much earlier stage than previously. If a patient shows evidence of peripheral circulatory failure or a persistent disorder of consciousness, or if we think he is likely to become seriously hypercarbic with the simple methods I mentioned, then he is bronchoscoped and a cuffed endotracheal tube is put down under local anaesthesia. He is then ventilated for $48 \mathrm{hr}$. We have found that this approach has greatly speeded up the recovery of patients that a year ago we would have treated in a more conservative manner, and has reduced dramatically the number of patients requiring tracheostomies and long periods of ventilation.

This brings me to my final point. Dr Howell has said that there is a world of difference in the ease of treating patients, on the one hand, in units with adequate staffing and all the advantages of blood-gas analysis and artificial ventilation, and, on the other, in hospitals with inadequate nursing staff and no ancillary aids. He says that no hospital where the mixed venous $\mathrm{PCO}_{2}$ cannot be measured should treat such patients. I am sure that this must exclude a great many hospitals in our region that admit many bronchitics each season, and it seems unlikely that they will have all the necessary equipment for some time. For this reason I think there is some urgency for the measurement of the effects of anoxia and hypercarbia on the various organs of the body, so that more concrete rules of therapy can be advocated for use in less well-equipped hospitals.

ABER. I think it should be appreciated that whereas the normal arterial oxygen tension in an ambulant patient is about $80-90 \mathrm{mmHg}$, this is not true of patients without cardio-pulmonary disease, or normal subjects for that matter, who retire to bed, in whom I have seen oxygen tensions between the $70-75 \mathrm{mmHg}$ mark within $2 \mathrm{hr}$. Hence if we consider anoxia to be present when the arterial oxygen tension drops below $70 \mathrm{mmHg}$, patients with myocardial infarction do not have far to go before becoming anoxic.

Secondly, I am not convinced that the group of patients who become anoxic and in whom one cannot improve matters with oxygen administration by mask or nasal catheter, is a small one. We have found that it is quite frequent to find this type of patient in whom we have not been able to produce satisfactory arterial oxygen tensions whilst they are breathing oxygen through a nasal catheter (up to $8 \mathrm{l} / \mathrm{min}$ ) or through a polymask or M.C. mask. It is only when one introduces triggered intermittent positive pressure ventilation that the arterial oxygen rises.

Thomas. I found the communications given by $\mathrm{Dr}$ McNicol and Dr Nixon interesting from many points of view, and provocative in some respects. The increasing attention to the subject of care and treatment of patients with acute myocardial infarction seems to be progressing along two main paths: first, the improvement of practical facilities for patient management, including the provision of intensive care units, electrocardiograph monitoring, warning systems-either electronic or humanand continuous supervision, both nursing and medical, to enable rapid handling of the more dramatic cardiac emergencies. The second main activity is the analysis of the fundamental physiology of the disease and the 